\title{
PROJETO DE LETRAMENTO: CONTRIBUIÇÃO PARA UMA APRENDIZAGEM SIGNIFICATIVA NA EDUCAÇÃO DE JOVENS E ADULTOS
}

Fernanda Lessa Pereira (UFF)

Resumo: Este artigo surgiu da necessidade de desenvolver uma proposta didática de ensino de escrita para alunos de Educação de Jovens e Adultos (EJA) da rede municipal de ensino do Rio de Janeiro. Sabe-se que o domínio das habilidades de leitura e, principalmente, de escrita, é necessário para viabilizar o desenvolvimento pessoal e profissional do educando. Crucial é que se consiga, por meio de um projeto de letramento, tornar esse alunado proficiente na leitura e na produção escrita de distintos gêneros discursivos; explorando, assim, o uso social da língua. Dessa forma, garante-se uma aprendizagem que faça sentido para o discente e contribui-se para que, em diversas atividades escolares ou extraescolares, ele esteja apto a fazer adequado uso dos mais diferentes gêneros textuais. Pretende-se, portanto, contribuir para um embasado e consciente ensino-aprendizagem de Língua Portuguesa com foco na construção de um cidadão crítico, autônomo e competente no uso do Português.

Palavras-chave: Competência textual; Projeto de letramento; Gêneros textuais; Uso social da língua.

\begin{abstract}
This article arises from the necessity in developing a didactic proposal of writing teaching for Young and Adults Education that are studying in the Rio de Janeiro's municipal teaching net. It is known that the lecture abilities domain and - mainly - writing ones, is necessary to make viable the student's personal and professional development. The decisive question is getting - by means of a letting Project - to make these students become proficient in lecture and in the writing production of distinct discursive genders, exploring, in this way, the social use of language. In this way, it is guaranteed a learning that cause sense to the student, contributing, to the in school and homework activities, this student fells that is ready to make use of the many different textual genders. It is intended, in this way, to contribute for a based and conscious teaching/learning of Portuguese language with
\end{abstract}


focus in the building of a critical, autonomous and competent citizen in Portuguese using.

Keywords: Textual competence; Letting Project; Textual genders; Social use of language.

\section{INTRODUÇÃO}

Este artigo se pauta na constatação de que muitos dos alunos matriculados em turmas de Educação de Jovens e Adultos (doravante EJA) não sabem usar adequadamente estratégias de escrita na produção de textos dos mais diversos gêneros que circulam em nosso dia a dia. Fundamental é que a escola opte por um trabalho embasado em um projeto de letramento, de modo que as aulas de Português explorem o uso efetivo e consciente de nossa língua materna, instrumentalizando esses jovens e adultos que, embora carreguem uma diversificada bagagem social, oriunda de suas experiências extraescolares, são desvalorizados pela própria comunidade escolar, já que seu histórico é repleto de reprovações ou de abandonos. A valorização do que já sabem é, pois, essencial para resgatar a autoestima e a vontade de eles concluírem seus estudos.

A pretensão deste artigo é demonstrar que o desenvolvimento do alunado está entrelaçado à aplicação de projetos de letramento, a qual trará avanços nas habilidades de leitura e, principalmente, de escrita dos aprendizes que 
frequentam essas turmas de EJA. O intuito a que queremos chegar é o de obterem-se testemunhos, um gênero textual da ordem do relatar, cujo domínio social é o da memória e o da documentação das experiências humanas vivenciadas, de acordo com Dolz e Schneuwly (2004). Acerca da capacidade de linguagem dominante, o gênero testemunho se enquadra na representação pelo discurso de experiências vividas, situadas no tempo. Os contemplados com essa intervenção didática foram os matriculados em duas turmas de EJA, equivalentes ao oitavo e ao nono anos do segundo segmento do ensino fundamental e pertencentes a um dos Centro Integrados de Educação Pública (CIEP), que fica em Manguinhos, bairro da periferia do Rio de Janeiro.

Quanto ao arcabouço teórico-metodológico, elementares são as postulações de Schneuwly e Dolz (2004), as quais nortearam a aplicação de sequências didáticas; de Soares (1999, 2004, 2007) e suas contribuições acerca do letramento; de Geraldi (1997) e seu olhar acerca da produção textual; de Tinoco (2008) e seus postulados acerca da aplicação de projetos de letramento; dos Parâmetros Curriculares Nacionais (doravante PCN, 1998), que fornecem recomendações capitais aos educadores; de Durante (1998) e seus conhecimentos sobre a escrita; de Kleiman (2000) e sua 
definição de que ao uso efetivo e competente da tecnologia da escrita; e da Lei de Diretrizes e Bases da Educação (LDB) 5692/71 e sua suprema contribuição para a modalidade de EJA.

Com nossa escolha pelo trabalho com gêneros textuais, fizemos uso da contribuição da Teoria do Texto, cujo objeto específico são os processos de construção textual, por meio dos quais os interlocutores criam sentidos e interagem entre si. Clara fica a importância da interação entre educador e seus aprendizes, estando todos envolvidos de modo cooperativo e participativo. Dessa forma, o trabalho realizado com as turmas fez uso de uma pesquisa-ação, também denominada intervenção, pautada nos estudos de Michel Thiollent (2011).

Este artigo, quanto à organização, está dividido em seis seções denominadas: 1) A trajetória da educação de jovens e adultos, em que se abordam os percalços enfrentados pela modalidade de EJA; 2) A problemática do analfabetismo e o letramento em EJA, em que se aborda a importância do uso social, efetivo e consciente da leitura e da escrita; 3) O foco da produção textual na EJA: a real situação comunicativa, em que se mostra a importância de solicitarem-se produções em que haja interação entre os interlocutores; 4) Etapas até se chegar às produções elaboradas pelos alunos, em que há exposição tanto dos exercícios aplicados às turmas quanto 
das duas produções escolhidas; 5) Considerações finais, em que há uma reflexão sobre as estratégias utilizadas para a produção do alunado; 6) Referências, em que se apresentam as fontes pesquisadas para a elaboração deste artigo.

\section{A TRAJETÓRIA DA EDUCAÇÃO DE JOVENS E ADULTOS NO BRASIL}

A trajetória da Educação de Jovens e Adultos no Brasil tem início na época do Império, com seus primeiros registros de ensino noturno para adultos, e é marcada pelas lacunas do complexo sistema educacional brasileiro.

De acordo com Paiva (2005),

$$
\begin{aligned}
& \text { historicamente, a educação de jovens } \\
& \text { e adultos vem assumindo concepções e } \\
& \text { práticas bastante diferenciadas. Da visão } \\
& \text { ainda muito corrente de que ela se faz para } \\
& \text { recuperar o tempo perdido daqueles que } \\
& \text { não aprenderam a ler e a escrever, passando } \\
& \text { pelo resgate da dívida social; até chegar à } \\
& \text { concepção de direito à educação para todos, } \\
& \text { da presente década, e do aprender por toda } \\
& \text { vida, as enunciações variaram, deixando, no } \\
& \text { entanto, no imaginário social, a sua marca } \\
& \text { mais forte, ligada à volta à escola, para fazer, } \\
& \text { no tempo presente, o que não foi feito no } \\
& \text { tempo de infância. (p.27) }
\end{aligned}
$$

De forma sucinta, o trajeto dessa modalidade, cuja visibilidade ainda hoje é mínima pelo fato de a oferta de um ensino formal ser direcionada aos cidadãos das classes socioeconômicas mais baixas, é repleto de embates e de 
algumas conquistas. Acerca destas, podemos dar destaque às seguintes: implantação do Ensino Supletivo, com direito a um capítulo específico para a EJA, na década de 70; reconhecimento da educação de adultos como um direito de cidadania; ampliação do dever do Estado com a EJA e consequente garantia de ensino fundamental obrigatório e gratuito para todos. Obviamente, tudo isso foi reflexo de constantes reflexões sobre que tipo de ensino está sendo ofertado aos que se matriculam nas turmas componentes da EJA. De acordo com Haddad (2007), “a Constituição de 1988 foi o espelho e o resultado desse processo, reconhecendo novos direitos e contemplando novas estruturas e processos de democratização do poder público" (2007, p.8).

Ademais, profissionais do nível central da Prefeitura da Cidade do Rio de Janeiro elaboraram Documentos Norteadores do Programa de Educação de Jovens e Adultos, com o propósito de orientar os professores que lecionam nesta singular modalidade. Nesse documento, citam-se três funções a serem desempenhadas pela EJA: equalizadora, qualificadora e reparadora. Nítida está a correlação desta última - que se refere à possibilidade de acesso à educação básica de qualidade a todos que não puderam concluí-la na idade certa - ao $3^{\circ}$ artigo da Nova LDB no 9.334/96, que propôs 
a igualdade de condições para o acesso e a permanência na escola, o pluralismo de ideias e de concepções pedagógicas, a garantia de padrão de qualidade, a valorização da experiência extraescolar e a vinculação entre a educação escolar, o trabalho e as práticas sociais. (BRASIL, 1996, p.1)

Para corroborar este artigo, que visa a valorizar a modalidade da EJA, cujas práticas escolares têm de ter respeito às especificidades de cada aluno, temos a visão de Schneider (2010) de que "na escola de EJA, jovens e adultos explicitam e constituem seus modos de relação com o conhecimento, com o projeto de educação que a sociedade tem para eles e que eles têm para si mesmos e com seus projetos de futuro [...]" (SCHNEIDER, 2010, p.8-9).

A tese de Schneider (2010) apresenta a dificuldade de jovens e adultos matriculados em turmas de EJA verem a escola como seu lugar, tendo noções de pertencimento ao universo escolar e de inclusão nesse espaço. Essa situação de desrespeito e de descaso com turmas da modalidade de EJA, observada por essa estudiosa, infelizmente está presente na unidade escolar onde foi aplicada a pesquisa. Concluímos que talvez, mesmo sem perceberem, muitos profissionais da educação não fazem um trabalho de conscientização com suas turmas, fato que contribui para 
a sensação de não pertencimento ao ambiente escolar por parte de muitos estudantes da EJA, o que acaba por levar uma grande parcela a abandonar a escola, aumentando o índice de evasão escolar.

\section{A PROBLEMÁTICA DO ANALFABETISMO E O LETRAMENTO EM EJA}

A avaliação da trajetória da EJA, abordada na seção anterior, faz com que se observem situações sociais do passado que se fazem presentes até os dias atuais, já que tais eventos levaram à formação de um hiato em nossa sociedade onde existem dois lados opostos, convivendo diariamente: os alfabetizados e os analfabetos. De acordo com a concepção de Soares (1999, p.19), "alfabetizado nomeia aquele que apenas aprendeu a ler e escrever, não aquele que adquiriu o estado ou a condição de quem se apropriou da leitura e da escrita" (1999, p.19). Além desses dois tipos, existem jovens e adultos que não conquistaram a competência linguística de saber ler, analisar e produzir seu próprio discurso escrito na idade certa, embora tenham, em seu dia a dia, criado estratégias para sobreviver em um mundo letrado e poliglota, que exige o domínio de uma série de habilidades textuais.

Apesar de tanta problemática, a forma de se obter um diploma de conclusão de etapas da educação básica, que não 
fora obtido no tempo esperado, é se fazer a matrícula em uma escola de ensino não seriado, ou seja, de modalidade de educação de jovens e adultos, ofertada por municípios e por estados brasileiros, que investem - ainda que sutilmente - no resgate dessa parcela populacional alijada, há tempos, da educação, mas que tem muito a ensinar com suas experiências adquiridas nos mais distintos eventos extraescolares de letramento.

Para compreendermos como pode um cidadão pertencer a um dos níveis de analfabetismo funcional e ainda assim ser letrado, teremos de recorrer aos estudos de Soares (2007) que declara que

passou a ser usada, particularmente na área acadêmica, a palavra letramento para designar esta outra faceta do processo de inserção no mundo da escrita: uma faceta é a aprendizagem do sistema de escrita (o sistema alfabético e o sistema ortográfico) - a alfabetização; outra faceta é o desenvolvimento de competências (habilidades, conhecimentos, atitudes) de uso efetivo desse sistema em práticas sociais que envolvem a língua escrita - o letramento. (p.104)

Essa assertiva mostra que dominar o código da escrita é muito pouco. Os jovens e adultos que não tiveram como frequentar uma escola na idade certa precisam fazer uso 
social, efetivo e consciente da leitura e da escrita e, ampliar seus níveis de letramento.

Acerca desses níveis, Soares (2004) designa que a alfabetização - a aquisição da tecnologia da escrita - não precede nem é pré-requisito para o letramento, isto é, para a participação em práticas sociais de escrita, tanto assim que analfabetos podem ter um certo nível de letramento: não tendo adquirido a tecnologia da escrita, utilizam-se de quem a tem para fazer uso da leitura e da escrita. (p.92)

Logo, é primordial expor a definição de letramento, conceituado por Soares (2004), da seguinte forma:

ao exercício efetivo e competente da tecnologia da escrita denomina-se letramento, que implica habilidades várias, tais como: capacidade de ler ou escrever para atingir diferentes objetivos - para informar ou informar-se, para interagir com outros, para imergir no imaginário, no estético, para ampliar conhecimentos. (p.91-92)

Para que o corpo discente tenha noção de tudo isso, imprescindível é a prática de produção textual, encorajada por meio de um projeto de letramento.

\section{O FOCO DA PRODUÇÃO TEXTUAL NA EJA: A REAL SITUAÇÃO COMUNICATIVA}

Os educadores que lecionam em turmas da modalidade de EJA têm de compreender que, embora os seus discentes 
apresentem dificuldades para a elaboração de um texto pertencente à modalidade escrita, eles têm características de pensamento letrado, posto que se envolvem em processos de mediação possibilitados pela interação com o meio, principalmente por residirem em núcleos urbanos, e pela função da língua dentro dos variados contextos sociocomunicativos dos quais participam.

Nosso embasamento teórico encontra respaldo em Durante (1998, p.28), que afirma terem os alunos que compõem essas turmas conhecimentos sobre a escrita como representação da língua, visto que fazem interação com a sociedade letrada. E isso é facilmente comprovado, uma vez que todos os professores sabem que seu alunado interage constantemente com outras pessoas em diversas redes sociais com bastante desenvoltura justamente por não terem a cobrança de avaliação e de sinalização dos inúmeros desvios cometidos.

Isso apenas comprova que a produção escolar necessita de mudanças que estimulem a vontade dos estudantes de escreverem textos que, de fato, tenham um verdadeiro propósito comunicativo e que não sejam, apenas, formas de avaliação. E exige dos professores novas estratégias de correção que não se resumam a apontamentos em vermelho 
a cada inadequação à norma-padrão encontrada. Quanto a isso, encontramos embasamento teórico em Geraldi (1997, p.135), que diferencia o que seja redação, ou seja, textos feitos para a mera avaliação escolar, do que seja produção de textos, que, apesar de serem feitos na escola, são voltados para uma real situação de comunicação. Acreditamos serem estes últimos os únicos que devem ser exigidos aos alunos, visto que ganham nova função, desconstruindo o peso de um desempenho, que normalmente é aquém do esperado. Uma de nossas sugestões é a troca de cartas entre turmas diferentes, o que leva a uma escrita mais leve e descompromissada. Válido é afirmar que esse gênero primário carta certamente faz com que os jovens e os adultos se interessem em produzir textos, cada vez mais, com a expectativa de um retorno de quem as recebe.

Sendo assim, podemos inferir que a produção de linguagem leva à produção do discurso, sendo este delimitado por uma série de fatores, tais como: o contexto, os conhecimentos e as características dos interlocutores envolvidos na produção de qualquer discurso. Crucial é o alunado entender que, independentemente do tamanho de um texto, o que o faz ser texto é apresentar coerência. Além disso, toda e qualquer manifestação linguística dos discursos se dá através 
de textos; sendo, pois, função do ensino de Português o desenvolvimento da competência textual dos aprendizes, que estarão habilitados a participarem, com a desenvoltura esperada, dos mais diversos eventos comunicativos. Com essas informações, cabe ao professor declarar aos estudantes - que são usuários da língua portuguesa que todo texto se organiza dentro de um gênero, que possui forma própria. Durante $(1998$, p.30) afirma que "os gêneros são determinados historicamente pelas intenções comunicativas nas produções de discursos de uso social. Os textos são ilimitados, tendo em vista as mudanças de uso e a função no processo social e cultural" (1998, p.30). É tarefa, portanto, da EJA fazer dos alunos usuários que planejam seu discurso, vinculando-o ao objetivo a que se dispõem. Tal recomendação consta dos PCN (1998).

Já que o foco do ensino-aprendizagem na EJA exige a implementação de um Projeto de Letramento, indispensável é sua definição:

Um conjunto de atividades que se origina de um interesse real na vida dos alunos e cuja realização envolve o uso da escrita [...] é uma prática social em que a escrita é utilizada para atingir outro fim, além de mera aprendizagem da escrita.

(KLEIMAN, 2000, p.238) 
Essa implementação ganha reforço com a opinião de Tinoco (2008, p.42) acerca do que seja o objetivo dos projetos de letramento: a resolução de um problema coletivo, tendo como ponto de partida um propósito comunicativo, que neste caso, foi a produção do gênero testemunho.

Esta proposta de projeto de letramento vai de encontro com práticas cuja abordagem faz com que os alunos produzam textos para a mera avaliação do professor, o que afasta os jovens e os adultos das aulas de língua materna e, em nada, contribui para a melhoria do ensino ofertado nas escolas públicas. Baseado nisso, este artigo pretender alterar o preocupante panorama observado em muitas rotinas escolares, de modo que a redação clássica possa ser substituída pela oferta, pelo conhecimento e pela produção de gêneros que fazem parte da vida de nosso alunado.

\section{ETAPAS ATÉ SE CHEGAR ÀS PRODUÇÕES ELABORADAS PELOS ALUNOS}

Dentre os gêneros que se enquadram no domínio social de comunicação chamado por Dolz e Schneuwly (2004) "documentação e memorização de ações humanas" (2004, p.121), optamos pelo testemunho, cuja capacidade de linguagem dominante é relatar, ou seja, tecer a representação pelo discurso de experiências vividas, situadas no tempo. 
Quanto ao projeto de letramento implementado, inevitável se fez a aplicação de um procedimento denominado "sequência didática", cuja definição dada por Schneuwly e Dolz (2004) é a seguinte: "um conjunto de atividades escolares organizadas, de maneira sistemática, em torno de um gênero textual oral ou escrito" (2004, p.82). As etapas que compõem uma sequência didática são estas: apresentação da situação; produção inicial; módulos e produção final.

Relevante é saber que várias foram as etapas a serem superadas até que o corpo discente produzisse seus testemunhos. E, como a professora precisava de apresentar exemplos para que os alunos se espelhassem em um texto com bastante semelhança, essa educadora escolheu um outro gênero, a sinopse, que, por ser pequeno e de fácil leitura, surtiu o efeito desejado: a vontade de eles relatarem as superações de cada um ao longo de suas vidas. Os jovens e adultos presentes foram convidados, portanto, a ler a sinopse de um filme a que muitos já haviam assistido: "Mais forte que o mundo". 
CIEP MUNICIPALIZADO BRIZOLÃO O15 HENRIQUE DE S FILHO HENFIL

ALUNO(A): Erabriel do Nanamente Mortes

TURMA: $y 52$ DATA: $23 / 10 / 2019$

PROFESSORA: Fernanda Lessa

Nota:

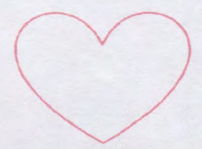

SINOPSE E DETALHES

Não recomendado para menores de 14 anos

Nascido e criado em Manaus, José Aldo (José Loreto) precisa lidar com a truculência do pai, Seu José (Jackson Antunes), que além de se embebedar constantemente ainda por cima bate na esposa, Rocilene (Cláudia Ohana), com frequência. Enfrentando constantemente seus demônios internos, Aldo encontra na luta sua válvula de escape. Acreditando em seu futuro como lutador, ele aceita se mudar para o Rio de Janeiro e morar de favor no pequeno alojamento de uma academia. Lá ele recebe o apoio do amigo Marcos Loro (Rafinha Bastos) e conhece Vivi (Cleo Pires), uma jovem que vai constantemente à academia. Precisando ralar um bocado para se manter, Aldo enfim consegue um voto de confiança do treinador Dedé Pederneiras (Milhem Cortaz), iniciando assim sua carreira no mundo do MMA.

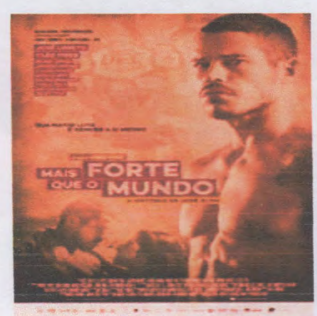

Quadro 1 - Sinopse do filme Mais Forte que o Mundo. ${ }^{1}$

Já que a história de José Aldo em muito se assemelha a de muitos dos integrantes das turmas de EJA, os discentes não sentiram dificuldade em escrever seu próprio testemunho. Sentiram-se, pois, estimulados e capazes de relatar sua própria jornada de vida, repleta de lutas e de superações.

Etapas para instrumentalizar os componentes das turmas foram aplicadas, a fim de serem minimizados inúmeros desvios linguísticos que apareceram na primeira produção. Inicialmente a observação de um enorme quantitativo de inadequações gramaticais pareceu à professora um obstáculo intransponível. Mas essa constatação é apenas uma amostra dos sérios problemas detectados diariamente em textos da modalidade escrita, fato que coíbe a vontade de escrever do alunado. É um excelente e primordial exercício de reflexão

1 Fonte: http://www.adorocinema.com/filmes/filme-241667/ 
para ser feito pelos docentes, que precisam criar estratégias pedagógicas capazes de não retroalimentar as reprovações por que passaram seus alunos até chegarem à modalidade da EJA.

Como meios para se diminuírem os desvios linguísticos encontrados, variados exercícios de correção de textos feitos pelos próprios alunos foram trabalhados. Obviamente, com todo cuidado para não se exporem os autores desses textos, fazendo-se, portanto, as devidas modificações. Todavia, esses exercícios foram importantes ferramentas para que os estudantes percebessem que a revisão faz parte do processo de qualquer produção textual da modalidade escrita. Recorrente é verificar que os aprendizes não estão familiarizados com o indispensável processo de revisão de seus textos, acreditando que uma única versão é suficiente para alcançarem o êxito esperado. Cabe uma outra reflexão sobre o papel do professor em sala, já que este deveria estar estimulando esse movimento de ler e de devolver os textos produzidos, sinalizando as inadequações e oportunizando aos estudantes as mudanças textuais. $O$ que se observa, infelizmente, é um trabalho de correção que desestimula qualquer aluno a produzir textos, que resultam normalmente em notas baixas. Dá-se um grau de importância maior às inadequações existentes em detrimento do conteúdo. 
Nas produções avaliadas, nítido está que, além de uma trajetória sofrida de vida, os jovens e adultos matriculados nestas turmas têm a capacidade de expressarem-se por meio da escrita. Quanto ao conteúdo dos testemunhos, inferimos que é possível ser feita, na escola, uma atividade de produção cujo intuito seja um texto real, que será, de fato, lido por outros usuários da língua.

Os exercícios trabalhados com os componentes das duas turmas do segundo segmento do ensino fundamental foram estes: 
Pontue as orações a seguir e justifique cada emprego de determinado sinal, usando esta legenda:

(1) vírgula para marcar vocativo;

(2) vírgula para marcar orações independentes;

(3) vírgula para marcar ideia de tempo, de lugar, de modo no início da oração;

(4) vírgula para marcar ideia de tempo, de lugar, de modo no meio da oração;

(5) ponto-final para oração declarativa;

(6) interrogação para oração interrogativa;

(7) exclamação para oração exclamativa.

a) O que achou aluno de aprender deste jeito Você está conseguindo entender esta matéria querido

b) No dia de ontem todos os alunos de repente ouviram tiros e tiveram de correr para o corredor Que desagradável

c) No Brasil a violência cresce absurdamente por quê amigo

d) Sinceramente professora eu acreditava que usar os sinais de pontuação não exigia conhecimentos de regras Que bom que estou entendendo

e) O que acha amigo de eu dar a você uma oportunidade de emprego

f) Os alunos chegaram ao CIEP foram ao refeitório jantaram rapidamente De repente ouviram muitos tiros Que perigo

Quadro 2 - Exercício para pontuar textos e justificar cada sinal usado. ${ }^{2}$

O próximo exercício visava à percepção da adequada variedade linguística a ser usada com as alterações necessárias, sem descaracterizar a informalidade do gênero bilhete.

2 Fonte: Elaboração da professora. (2019). 


\section{Bilhete 1}

Querida prof

Sou Ana de Sousa sua aluna do CIEP JK e gostaria de contar à vc o seguinte arrumei um trabalho as noites e porisso não vou ir mas a escola sei que a senhora entende eu por causa de que tá difícil de arruma enprego hoje em dia derrepente Si dé passo ai para lhe dá um abraço muito obrigado por tudo

\section{Ass. Ana De sousa}

Bilhete 2

- Oi amiga tudo bem

- Vc soube quem a garota estava fica no com meu amigo é minha prima

- Nossa mãe não sabia

- Mudando de assunto vou pedi uma pizza de mussarela para comer vem prá ca

- Tu sabe que eu ti consideru minha amiga quer vim

- Tô indo, não come tudo me espera

$-B L Z$

Quadro 3 - Exercício para pontuar e para adequar o texto à variedade linguística. ${ }^{3}$

Passadas essas etapas de revisão textual, chegou o momento de os estudantes escrevem seus testemunhos em poucas linhas para não haver desculpas ou negativas. Dos textos produzidos, serão expostos dois, que servem de exemplos da capacidade de os estudantes relatarem suas trajetórias de vida.

O primeiro texto explicita o nome do aluno. Ei-lo:

3 Fonte: Elaboração da professora (2019). 


\begin{tabular}{|c|c|}
\hline 1 & houciano é um nupas da cidade de \\
\hline 2 & Rio de Manciro que sempere tuton por ter uma \\
\hline 3 & Vole soudáned. Oor nover anos de idade benden sen \\
\hline 4 & pai, tundo que trabalhas munto cedo, pois \\
\hline 5 & eira, nai timba dimkiro \\
\hline 6 & para comprar sur pró \\
\hline 7 & Sua vide ficon ainda mais diffícilo fui quando \\
\hline 8 & ars 17.amos de idade cle \\
\hline 9 & qun acabou en \\
\hline 10 & que pensar como se fosse uma pessoa adult. \\
\hline 11 & 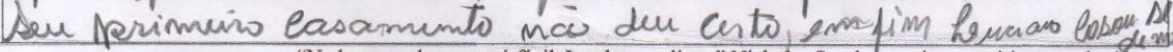 \\
\hline
\end{tabular}

Quadro 4 - Produção de gênero testemunho. ${ }^{4}$

Com o propósito de revisar o texto, a professora digitou-o e, juntamente com o produtor do texto, fez as mínimas alterações, a fim de não mudar totalmente o que fora escrito pelo aprendiz. Foi uma estratégia que resultou em alívio e em fortalecimento da autoestima do estudante, acostumado a ter seu texto quase que totalmente desfigurado pelas mãos do educador.

4 Fonte: Elaboração de um aluno de EJA. (2019). 
Luciano é um rapaz da cidade do Rio de Janeiro e sempre lutou por ter uma vida saudável. Aos nove anos de idade, perdeu seu pai, tendo que trabalhar muito cedo; pois, sem condição financeira, não tinha dinheiro para comprar seu próprio material escolar. Sua vida ficou ainda mais difícil, quando aos 17 anos de idade, ele namorou uma menina que acabou engravidando dele. Luciano, então, teve que pensar como se fosse uma pessoa adulta. Seu primeiro casamento não deu certo, mas Luciano se casou de novo.

Quadro 5 - Produção revisada de testemunho de aluno. ${ }^{5}$

O segundo texto, cuja autoria não está explicita no corpo do texto, encontra-se a seguir:

\begin{tabular}{|c|c|}
\hline 1 & 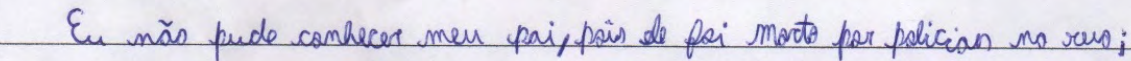 \\
\hline 2 & ei que nào tinko mais familir, pois minhs minho mâ \\
\hline 3 & am lange dos neus tar e primar, Quchei sue ero ró \\
\hline 4 & 416 anos, reencantrei meus pacentes se minks \\
\hline 5 & 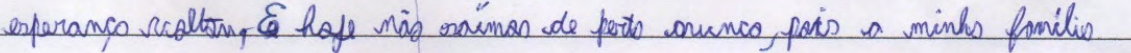 \\
\hline 6 & suen reacuperar o tempo perdido sue licanas lange minks \\
\hline 7 & famélis é muito gande, comporta de mais de cinquenta perraas \\
\hline 8 & degerrete tias, unas sui \\
\hline 9 & 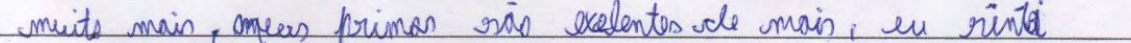 \\
\hline 10 & mite raredade \\
\hline 1 & \\
\hline
\end{tabular}

"Nada que vale a pena é fácil. Lembre-se disso." Nicholas Sparks, escritor, roteirista estadunidense

Quadro 6-Produção de testemunho de aluno. ${ }^{6}$

5 Fonte: Elaboração da professora, com a ajuda do aluno. (2019).

6 Fonte: Elaboração de um aluno de EJA. (2019). 
Outra intervenção feita pela professora com a ajuda do aluno, objetivando mudar o mínimo possível e preservando, assim, as escolhas lexicais e sintáticas do produtor do texto é a seguinte:

Eu não pude conhecer meu pai, pois ele foi morto por policiais na rua; depois disso, eu achei que não tinha mais família, pois minha mãe se mudou de casa para bem longe dos meus tios e primos. Achei que era só eu e minha mãe; depois de 16 anos, reencontrei meus parentes, e minha esperança voltou. E hoje não saímos de perto nunca, pois a minha família quer recuperar o tempo perdido em que ficamos longe. Minha família é muito grande, comporta de mais de cinquenta pessoas; só em Austin, tenho dezessete tias, uns tios e muito mais. Meus primos são excelentes demais; eu senti muita saudade deles, eles são demais.

Quadro 7 - Produção revisada de testemunho de aluno. Fonte: Elaboração da professora, com a ajuda do aluno. (2019).

\section{CONSIDERAÇÕES FINAIS}

A partir da pesquisa apresentada, pudemos perceber que a intervenção didática, aplicada por meio de um projeto de letramento, favoreceu um progresso notável na participação e na interação dos componentes dessas duas turmas de EJA. Constatamos que esse projeto contribuiu de modo significativo para o processo de ensino-aprendizagem dos jovens e dos adultos envolvidos, que se mostraram efetivamente interessados em participar das atividades propostas.

Válido é dizer que a aplicação da sequência didática nas duas turmas foi uma escolha enriquecedora, posto que forneceu à professora, dentre tantas informações, Caderno Seminal Digital, no 36, v. 36 (JUL-DEZ/2020) - e-ISSN 1806-9142 
o seguinte: dados capazes de demonstrar o que de fato é apreendido por esses jovens e adultos que frequentam esse tipo de modalidade de ensino; o limite atingido pela educação formal pensada como abertura a novos horizontes para um alunado deveras heterogêneo; a delimitação das arestas que ainda precisam ser aparadas para que, de fato, o estudante que se matricula nessa modalidade possa ter a garantia de que apreendeu conhecimentos que lhe serão essenciais nos mais diversos eventos de letramento pelos quais passará.

A abordagem metodológica aplicada implica uma visão de que a modalidade de EJA pode e deve ser vista como um ensino tão eficaz quanto ao das turmas seriadas; uma vez que propicia a cada aluno, a seu tempo e modo, ser agente da tão almejada aprendizagem significativa, útil para a ascensão social e, principalmente, profissional desse alunado estigmatizado e com poucas oportunidades de concorrer no exigente mercado de trabalho, que quase sempre é a mola impulsora do retorno desses aprendizes aos bancos escolares.

\section{REFERÊNCIAS}

BRASIL (1971). Misnistério da Educação, Lei de Diretrizes e Bases da Educação, Lei no 5692/1971, de 11 de agosto de 1971.

BRASIL (1998). Ministério da Educação, Secretaria de Ensino Fundamental. Parâmetros Curriculares Nacionais: ensino fundamental. Brasília: Ministério da Educação. 
DOLZ, Joaquim; NOVERRAZ, Michèle; SCHNEUWLY, Bernard (2004). "Sequências Didáticas para o oral e a escrita: apresentação de um procedimento". In: SCHNEUWLY, Bernard; DOLZ, Joaquim. (Orgs.) Gêneros orais e escritos na escola. Campinas, SP: Mercado de Letras, p.81-108. DURANTE, Marta (1998). Alfabetização de adultos: leitura e produção de textos. Porto Alegre: Grupo A.

GERALDI, João Wanderley (1997). Portos de passagem. 4.ed. São Paulo: Martins Fontes.

HADDAD, Sérgio (Coord.) (2007). Novos caminhos em Educação de Jovens e Adultos. São Paulo: Global.

KLEIMAN, Angela (2000). "O processo de aculturação pela escrita: ensino da forma ou aprendizagem da função?" In: KLEIMAN, A.; SIGNORINI, I. (Orgs.). $O$ ensino e a formação do professor: alfabetização de jovens e adultos. Porto Alegre: Artmed.

PAIVA, Jane; OLIVEIRA, I. B. (2005). Educação de jovens e adultos: Direito, concepções e sentidos. (Tese - Doutorado). Faculdade de Educação, Niterói, RJ: UFF.

SCHNEIDER, Sônia M. (2010). Esse é o meu lugar... Esse não é o meu lugar: relações geracionais e práticas de numeramento na escola de EJA. 221p. (Tese - Doutorado) Faculdade de Educação, UFMG, Belo Horizonte. In portal.mec.gov.br/secad/arquivos/pdf/eja/.../parecer_11_2000.pdf. Acesso em: 25.Ago.2019.

SOARES, Magda (1999). "Letramento em verbete: O que é letramento?" In: Letramento: um tema em três gêneros. São Paulo: Autêntica, p.14-25. (2004). "Letramento e escolarização". In: RIBEIRO, Vera Masagão. (Org.) Letramento no Brasil. 2.ed. São Paulo: Global, p.89-113. (2007). "Alfabetização". In: PINSKY, Jaime (Org.). O Brasil no contexto: 1987-2007. São Paulo: Contexto, p.99-107.

THIOLLENT, Michel (2011). Metodologia da pesquisa-ação. 18.ed. São Paulo: Cortez.

TINOCO, Glícia M. Azevedo de M. (2008). Projetos de letramento: ação e formação de professores de língua materna. Campinas, SP: [s.n.]. 


\section{LISTA DE SIGLAS}

\begin{tabular}{|l|l|}
\hline CIEP & Centro Integrado de Educação Pública \\
\hline EJA & Educação de Jovens e Adultos \\
\hline LDB & Lei de Diretrizes e Bases da Educação \\
\hline PCN & Parâmetros Curriculares Nacionais \\
\hline
\end{tabular}

Fernanda Lessa Pereira é Doutoranda em Estudos de Linguagem, pela UFF e possui título de Mestra em Letras pela UFRRJ/Seropédica (2016). Atualmente está como professora de Língua Portuguesa nas Prefeituras Municipais da Cidade do Rio de Janeiro e de Duque de Caxias. Como produção acadêmica, há o artigo, elaborado juntamente com a orientadora de Mestrado Marli Hermenegilda Pereira, publicado na Seda Revista de Letras da Rural, campus Seropédica/RJ. Também publicou, com coautoria de Daiane Alves Cordeiro Brites, Sequências tipológicas, gêneros textuais e ensino de produção de textos: uma tríade essencial para a obtenção da competência metagenérica dos alunos do segundo segmento do ensino fundamental em suas práticas sociocomunicativas, artigo que faz parte do livro Pesquisa e ensino: parceria ou dicotomia? da Editora da UFRRJ.

Lattes: 9645239540151921

E-mail: lessafp@gmail.com

ORCID iD: https://orcid.org/0000-0001-5056-307X 